\title{
Quantitative Analysis of Toxicants in Major Tobacco Products Available in Bangladesh
}

\author{
M M Islam, M A Islam*, P Biswas, S T Auyon \\ Department of Environmental Science, Bangladesh Agricultural University, Mymensingh, Bangladesh \\ *Corresponding Author: M A ISLAM, Department of Environmental Science, Bangladesh Agricultural \\ University, Mymensingh, Bangladesh
}

\begin{abstract}
Tobacco is an industrial plant which has the ability to accumulate metals. The present study was undertaken to identify and quantify the toxicant substances available in selected tobacco products. Four major tobacco products (Loose leaf, Zarda, Cigarette and Bidi) were collected from four districts (Dhaka, Kushtia, Chittagong and Rangpur) of Bangladesh to analyze the contents of different chemicals $(\mathrm{Pb}, \mathrm{Cd}, \mathrm{Zn}$ and $\mathrm{Ni}$ ). The samples were cleaned, extracted and analyzed in the laboratory of Bangladesh Agricultural University using Gas Chromatography $(G C)$, High Performance Liquid Chromatography (HPLC) and Atomic Absorption Spectrophotometer (AAS). The laboratory analysis revealed there was higher content of nicotine and metals [Lead $(\mathrm{Pb})$, Cadmium $(\mathrm{Cd})$ and Nickel $(\mathrm{Ni})$ ] in loose leaf tobacco compared to bidi, zarda and cigarette samples. Tar content was found to be higher in bidi than other products studied. Average Pb content of tobacco products ranged from 4.71 to 18.67 part per million (ppm). Average Zn content of the study area was higher in zarda sample than in others. The average amount of $\mathrm{Pb}, \mathrm{Ni}, \mathrm{Zn}$ and $\mathrm{Cd}$ in tobacco products were found higher than the recommended permissible limits. To compare the regional variation, the average concentration of $\mathrm{Pb}, \mathrm{Cd}, \mathrm{Zn}$ and $\mathrm{Ni}$ found in different tobacco products of Dhaka were ranged from 1.32-16.9, 1.49-3.49, 42.3-82.34 and 0.43-26.6 $\mathrm{mg} / \mathrm{L}$ respectively whereas the concentration of these chemicals obtained from different tobacco products of Chittagong were ranged from 1.19-18.6, 1.07-3.18, 31.88-89.6 and 0.77$27.7 \mathrm{mg} / \mathrm{L}$ respectively. Similarly, the average concentration of $\mathrm{Pb}$ ranged from $1.02-15.5 \mathrm{mg} / \mathrm{L}$ and the concentrations of $\mathrm{Cd}$, $\mathrm{Zn}$ and $\mathrm{Ni}$ were ranged from 0.98-3.02, 30.13-80.7, 0.86-25.00 $\mathrm{mg} / \mathrm{L}$ respectively in the tobacco products of Kushtia. In case of Rangpur the average concentrations of $\mathrm{Pb}, \mathrm{Cd}, \mathrm{Zn}$ and Ni for the selected tobacco products were ranged from 1.25-18.7, 1.24-3.82, 28.9-97.2 and 0.39-20.5 mg/L respectively. The average amount of toxicants in tobacco products exceeds the recommended permissible limits. These results emphasized the importance of strengthening the existing policy considering adverse health effects of those examined toxicants contained in tobacco products.
\end{abstract}

Keywords: Tobacco products, Loose leaf, Zarda, Cigarette, Bidi, Metals

\section{INTRODUCTION}

Nicotiana tabacum is an herbaceous plant in the Solanaceae (nightshade family) that originated in the tropical Americas and is now cultivated worldwide as the primary commercial source of tobacco (FAO, 2000). But the matter of concern is that at present, tobacco is the single greatest cause of death around the world and sources of momentous adverse effect on human health including maternal and child death (WHO, 2008).

Tobacco was inaugurated in Bangladesh in the middle of the $19^{\text {th }}$ century and its usage has increased over the last four decades (Hossain et al., 2018). There are 41.1 million people using tobacco in Bangladesh, of which 20.9 million people are consuming tobacco either through cigarettes or bidis or both (ITC, 2010). The use of smokeless tobacco such as shada-pata, zarda is also very popular in Bangladesh however smoke free tobacco users are exposed to higher level of nicotine than smokers. Smoking and passive smoking are equally the biggest avoidable cause of death in Bangladesh, with major public health burden of morbidity, disability, mortality and community costs (WHO, 2007). The approximate number of deaths caused by tobacco is 57,000 on an average per year, and this number will rise soon. Another study assessed that cigarette smoking is responsible for around 25.0\% and $7.6 \%$ of deaths in males and females, respectively in Bangladesh (WHO, 2007). Every year more than 92,100 of its people are killed by tobacco-caused disease, while more than 164,000 children and more than 254,92,000 adults continue to use tobacco each day (WHO, 2017). Besides that the 
prevalence of smoking amid the students frightening in Bangladesh which comprises the aged 18 to 26 (December 25, 2016, The Daily Star).

Tobacco smoking is being a worldwide problem with 1.3 billion people currently smoking cigarettes and one person loosing life every 6 second due to tobacco related illnesses (Kalicanin et al., 2005). It is reported that tobacco usage accounted for $4.1 \%$ of the global burden of ill-health in 2000 (Zaman and Nargis, 2007). Almost 4.9 million deaths in 2000 were attributed to tobacco usage (Ezzati et al., 2002). According to a recent study on smokers, the average loss of life expectancy per tobacco related illness in India was estimated at 20 years, with middle-aged smokers having twice the death rates than non-smokers (Gajalakshmi et al., 2003). There are many reports that indicate the increasing trend of use of tobacco products and their impacts on human health as well as economy (Murray and Lopez, 1996). Toxic metals in biomass burning and household dusts (Miah et al., 2019), in river water and fish species (Rahman et al., 2016), in vegetables (Uddin et al., 2015) were reported in Bangladesh. Studies in the People's Republic of China and India have shown that tobacco contributes to the incidence of pulmonary tuberculosis (Gajalakshmi et al., 2003). Studies in several countries observed that up to $17 \%$ of household income was being spent on tobacco products (De-beyer et al., 2001). A study in Bangladesh estimated that 10 million people currently malnourished could have an adequate diet if money spent on tobacco were spent on food instead (Effroymson et al., 2001).

In developed countries the qualitative and quantitative analysis were reported by different analytical and environmental experts for creating awareness on negative impacts of tobacco smoking on health and environment as well. But the research works on contents in tobacco products and their health as well as environmental impacts were not extensively studied in Bangladesh. Keeping these views in mind the study was undertaken to identify and quantify the chemical substances available in major tobacco products in Bangladesh context.

\section{Materials AND Methods}

\subsection{Site Selection and Sample Collection}

To conduct the present study, four districts (Dhaka, Kushtia, Chittagong and Rangpur) of Bangladesh were selected. The sampling sites were selected based on tobacco production and processing as well as tobacco consumption. Available four major tobacco products namely Loose leaf, Zarda, Cigarette and Bidi were selected and for each item three samples were collected from the selected districts. Finally solutions were extracted from all those samples to analyze the chemical content

\subsection{Extraction Procedure and Analysis of Metals}

At first, loose leaf tobacco samples were cleaned properly to remove the impurities, later cut into small pieces and dried by sunlight below temperature $40^{\circ} \mathrm{C}$ and grinding. Exactly $1 \mathrm{~g}$ of each tobacco samples were taken into petri-dishes plates and di-acid mixture $(\mathrm{HNO}: \mathrm{HClO} 4=10 \mathrm{ml}: 5 \mathrm{ml})$ was added to them and kept overnight. Then the samples were heated at a temperature of $150^{\circ} \mathrm{C}$ to prepare extracted solution and then cooled. After cooling, the extracted solutions were filtered to remove unwanted suspended materials and were made up to $50 \mathrm{ml}$ volume by deionized water for analyzing heavy metals content $(\mathrm{Pb}, \mathrm{Cd}, \mathrm{Zn}$ and $\mathrm{Ni})$ with the help of Atomic Absorption Spectrophotometer (AAS) model (AA 7000) in accordance with the standard procedure.

\section{RESULTS AND DISCUSSION}

\subsection{Chemical Contents in Loose Leaf Tobacco}

The average concentration of four selected metals $(\mathrm{Pb}, \mathrm{Cd}, \mathrm{Zn}$ and $\mathrm{Ni})$ obtained from the samples of loose leaf tobacco products of selected districts are represented in (Fig. 1). The average concentration of $\mathrm{Pb}$ found in different samples were ranged from 15.5 to $18.7 \mathrm{mg} / \mathrm{L}$ of which the highest concentration was observed in loose leaf tobacco products of Chittagong and the lowest was in that of Kushtia.This concentrations are similar to the reported concentration of $\mathrm{Pb}$ found in another study (Zhang et al., 2005) and are smaller than the concentrations reported for $\mathrm{Pb}$, found in tobacco leaves of India and Germany (Musharraf et al., 2012; Murty et al., 1986). In case of Cd the average concentrations were ranged from 3.02 to $3.82 \mathrm{mg} / \mathrm{L}$, the highest of which was observed in the samples of Rangpur. This concentrations are similar to that of $\mathrm{Cd}$ found in tobacco leaves of Canada and are smaller than the concentrations of Cd reported in previous study (Murty et al., 1986; Saldivar et al., 
1991). The average concentrations of another chemicals $\mathrm{Zn}$ were ranged from 76.3 to $85.7 \mathrm{mg} / \mathrm{L}$, among which the highest concentration was observed in the samples of Rangpur and the lowest was in that of Chittagong. The average concentrations of Ni were ranged from 20.5 to $27.7 \mathrm{mg} / \mathrm{L}$ of which the highest concentration was observed in the samples collected from Chittagong and the lowest was in that of Rangpur. The concentrations of $\mathrm{Zn}$ found in this study were similar to that of another study and were higher than the reported concentrations of $\mathrm{Zn}$ found in smokeless tobacco products (Nnorom, 2015; Musharraf et al., 2012) whereas the concentrations of another examined chemical Ni have been found relatively higher than the concentrations of Ni reported in several studies (Musharraf et al., 2012; Regassa and Chandravanshi, 2016; Stojanovic et al., 2004).

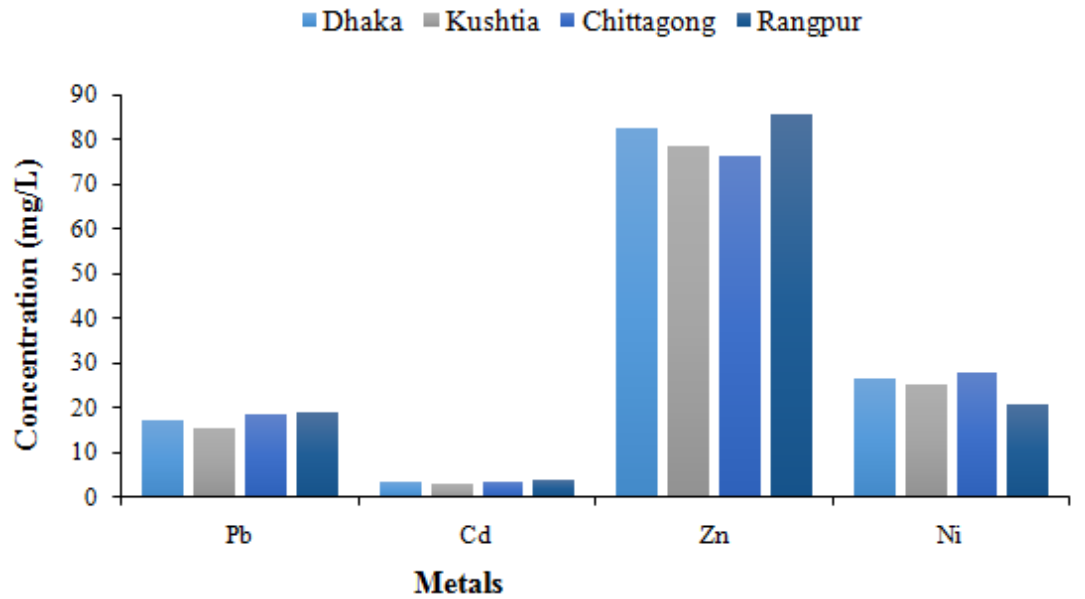

Fig1. Average concentrations of metals in loose leaf tobacco

\subsection{Chemical Contents of Zarda Tobacco Products}

The following figure (Fig. 2) represents the average chemical contents $(\mathrm{Pb}, \mathrm{Cd}, \mathrm{Zn}$ and $\mathrm{Ni}$ ) of zarda tobacco products collected from selected districts. The average concentrations of $\mathrm{Pb}, \mathrm{Cd}, \mathrm{Zn}$ and $\mathrm{Ni}$ obtained from this study were ranged from 7.38 to $8.67,1.94$ to $3.41,65.9$ to 97.2 and 15.2 to 18.7 $\mathrm{mg} / \mathrm{L}$ respectively for zarda tobacco products of Dhaka, Kushtia, Chittagong and Rangpur districts. For $\mathrm{Pb}$, the highest concentration was observed in the samples of Rangpur and the lowest was in that of Dhaka and Kushtia. In case of Cd the highest concentration was observed in the samples of Dhaka and the lowest was in that of Chittagong whereas for $\mathrm{Zn}$ the highest and the lowest concentration was obtained from the samples of Rangpur and Dhaka respectively. Zarda tobacco products collected from Chittagong contained a relatively high concentration of $\mathrm{Ni}$ whereas the samples collected from Rangpur contained the lowest. The concentrations obtained from the present study for different chemicals contained in zarda tobacco products were similar to the reported concentrations of those chemicals (Hossain et al., 2018; Prabhakar et al., 2013). Edrydstephens and Calder (2005) studied the average concentrations of different metals in tobacco leaves and those were lower than the present study.

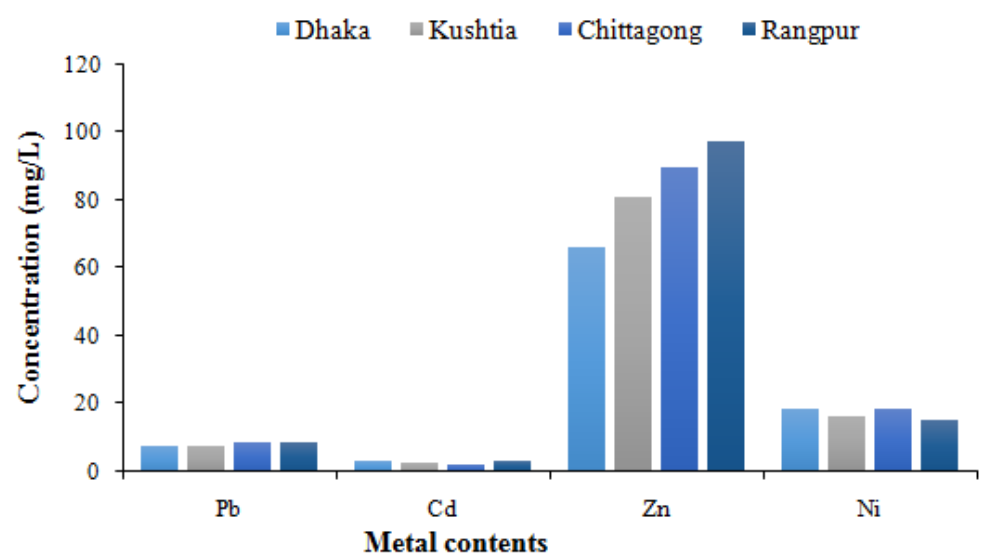

Fig2. Average concentrations of metals in Zarda (tobacco product) of selected districts 


\subsection{Chemical Contents of Cigarette Products}

In this study, the average concentrations of $\mathrm{Pb}, \mathrm{Cd}, \mathrm{Zn}$ and $\mathrm{Ni}$ obtained from different samples of cigarettes were ranged from 1.19 to $2.06,0.98$ to $2.4,45.18$ to 48.13 and 0.39 to $0.86 \mathrm{mg} / \mathrm{L}$ respectively for Dhaka, Kushtia, Chittagong and Rangpur districts (Fig. 3). For Pb and Zn, the highest concentration was observed in the samples of Kushtia among all the selected districts and this stands true not only for these two but also for another selected chemical Ni. In case of $\mathrm{Cd}$, the highest concentration was observed in the samples of Chittagong district than all other districts. The concentrations of $\mathrm{Pb}, \mathrm{Zn}$ and $\mathrm{Cd}$ obtained from this study were similar to the reported concentrations of these metals (Lazarevic et al., 2012; Jung et al., 1998; Watanabe et al., 1987) and for Ni it was found smaller than the reported concentration of Ni (Stojanovic et al., 2004). Iwuoha et al. (2013) analyzed the concentrations of different metals $(\mathrm{Zn}, \mathrm{Pb}$ and $\mathrm{Ni}$ ) contained in cigarette tobacco products and those were higher than the present findings.

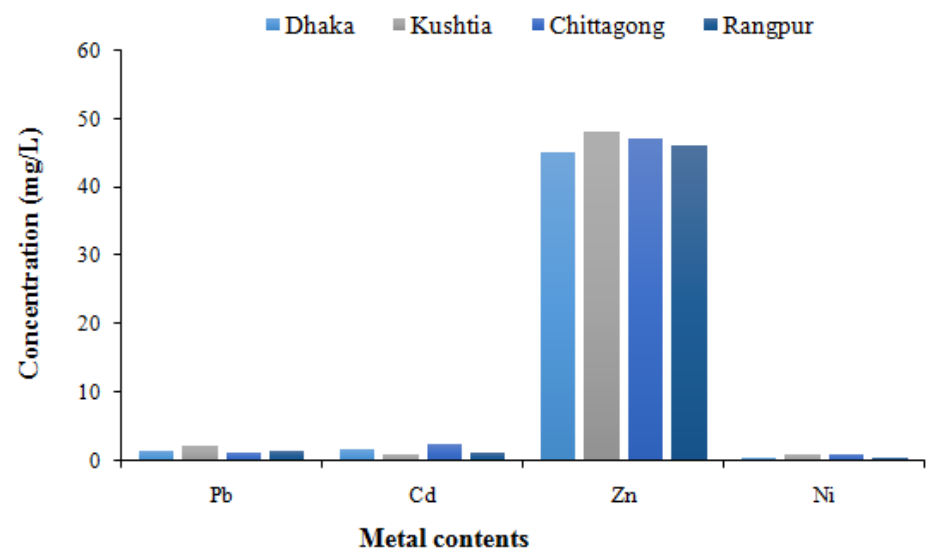

Fig3. Average metal concentrations of cigarette collected from selected districts

\subsection{Chemical Contents of Bidi}

It was observed that the average concentration of different chemicals obtained from different tobacco products were varied from each other. The average concentrations of $\mathrm{Pb}, \mathrm{Cd}, \mathrm{Zn}$ and $\mathrm{Ni}$ obtained from different samples of bidi which were ranged from 1.02 to $2.13,1.07$ to $2.19,28.9$ to 42.3 and 1.33 to $3.11 \mathrm{mg} / \mathrm{L}$ respectively (Fig. 4). For $\mathrm{Pb}$ and $\mathrm{Zn}$, the highest concentration was observed in the samples of Dhaka among all the selected districts and the lowest concentration was observed in that of Kushtia and Rangpur respectively whereas for $\mathrm{Cd}$ the highest concentration was found in the samples of Kushtia. In case of Ni the highest concentration was obtained from the samples of Chittagong the lowest from that of Dhaka among all districts. The concentrations obtained for $\mathrm{Pb}, \mathrm{Cd}$ and $\mathrm{Zn}$ in this present study are similar to that of these metals reported in different studies (Hossain et al., 2018; Mussalo-Rauhamaa et al., 1986). Dobaradaran et al., (2017) studied the chemical contents (Cd, Ni and $\mathrm{Zn}$ ) of smoked tobacco products which was similar to the present findings of $\mathrm{Ni}$ and was smaller than that of $\mathrm{Cd}$ and $\mathrm{Zn}$.

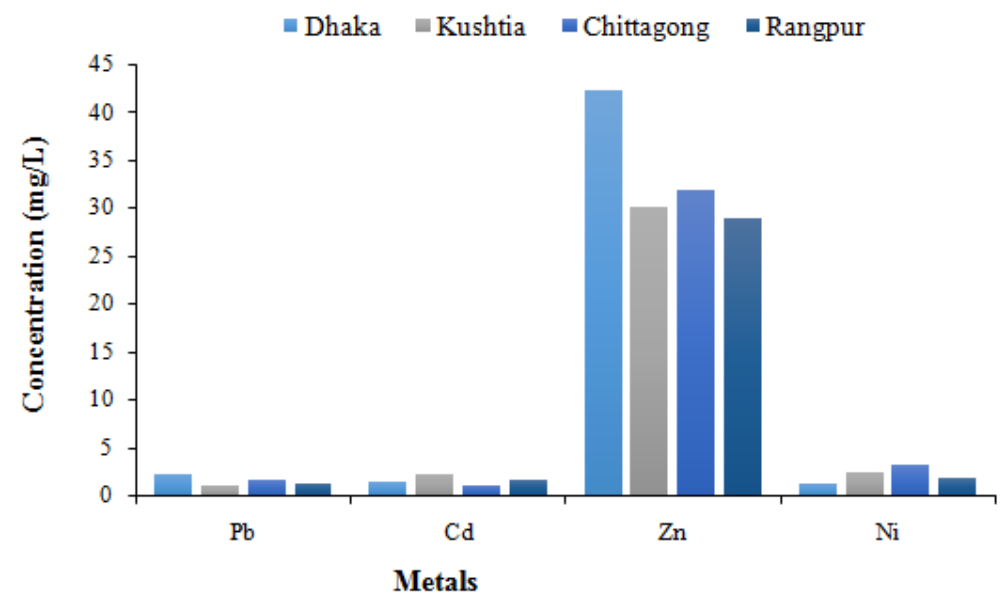

Fig4. Average metal contents of bidi collected from different districts in Bangladesh 


\subsection{Comparison Between Chemical Contents of Different Tobacco Products}

The concentrations of different chemicals obtained for selected tobacco products in this present study are represented in (Table 1). For $\mathrm{Pb}$, the highest concentration was observed in the samples of loose leaf tobacco products among all the selected tobacco products and the lowest was in the samples of bidi. Among the loose leaf tobacco products the highest concentration of $\mathrm{Pb}$ was obtained from the samples of Rangpur and the lowest from the samples of Kushtia. In case of Cd the highest concentration was obtained from the samples of loose leaf tobacco products and the lowest concentration was obtained from that of cigarettes than the other tobacco products. Loose leaf tobacco products collected from Rangpur contained a relatively high concentration of $\mathrm{Cd}$ whereas the cigarettes collected from Kushtia exhibited the lowest. Another analyzed chemical Zn, contained in zarda tobacco products at a concentration relatively higher than the other selected tobacco products. The lowest concentration of $\mathrm{Zn}$ is obtained from the samples of bidi. The zarda and bidi tobacco products collected from Rangpur district exhibited a comparatively higher and lower concentration of $\mathrm{Zn}$ respectively. Finally for Ni, the highest concentration was observed in the samples of loose leaf tobacco products and the lowest was in the samples of cigarettes than the other tobacco products. Loose leaf tobacco products collected from Chittagong contained a relatively high concentration of $\mathrm{Ni}$ whereas the cigarettes collected from Rangpur exhibited the lowest concentration.

Table1. Comparison on metal contents in different tobacco products collected from study sites

\begin{tabular}{|c|c|c|c|c|c|}
\hline \multirow{2}{*}{$\begin{array}{l}\text { Metal } \\
\text { Name }\end{array}$} & \multirow{2}{*}{ Districts } & \multicolumn{4}{|c|}{ Tobacco Products (ppm) } \\
\hline & & Loose leaf & Zarda & Cigarette & Bidi \\
\hline \multirow{4}{*}{$\mathrm{Pb}$} & Dhaka & 16.9 & 7.38 & 1.32 & 2.13 \\
\hline & Kushtia & 15.5 & 7.38 & 2.06 & 1.02 \\
\hline & Chittagong & 18.6 & 8.62 & 1.19 & 1.59 \\
\hline & Rangpur & 18.7 & 8.67 & 1.51 & 1.25 \\
\hline \multirow{4}{*}{$\mathrm{Cd}$} & Dhaka & 3.49 & 3.41 & 1.7 & 1.49 \\
\hline & Kushtia & 3.02 & 2.92 & 0.98 & 2.19 \\
\hline & Chittagong & 3.18 & 1.94 & 2.4 & 1.07 \\
\hline & Rangpur & 3.82 & 2.99 & 1.24 & 1.6 \\
\hline \multirow{4}{*}{$\mathrm{Zn}$} & Dhaka & 82.4 & 65.9 & 45.18 & 42.3 \\
\hline & Kushtia & 78.4 & 80.7 & 48.13 & 30.13 \\
\hline & Chittagong & 76.3 & 89.6 & 47.22 & 31.88 \\
\hline & Rangpur & 85.7 & 97.2 & 46.09 & 28.9 \\
\hline \multirow{4}{*}{$\mathrm{Ni}$} & Dhaka & 26.6 & 18.3 & 0.43 & 1.33 \\
\hline & Kushtia & 25 & 16.4 & 0.86 & 2.39 \\
\hline & Chittagong & 27.7 & 18.7 & 0.77 & 3.11 \\
\hline & Rangpur & 20.5 & 15.2 & 0.39 & 1.8 \\
\hline
\end{tabular}

The result also revealed that among all the analyzed chemicals $\mathrm{Zn}$ contained in almost all samples at a concentration $(97 \mathrm{mg} / \mathrm{L})$ relatively higher than the others whereas for $\mathrm{Ni}$ the concentration $(0.39$ $\mathrm{mg} / \mathrm{L}$ ) was the lowest. In case of analyzed tobacco products (Loose leaf, Zarda, Cigarette and Bidi), loose leaf tobacco products contained almost all chemicals only except $\mathrm{Zn}$ at a concentration relatively higher than the others whereas cigarettes $(\mathrm{Cd}, \mathrm{Ni})$ and bidi $(\mathrm{Pb}, \mathrm{Zn})$ contained a relatively lower concentration of these chemicals. Besides that, the samples of tobacco products collected from Rangpur district contained almost all chemicals except $\mathrm{Ni}$ at a concentration relatively higher than the other districts. This variation in concentration may due to some factors such as $\mathrm{pH}$ value, types of tobacco, the chemical composition of the metal, soil structure and geographical area of tobacco leaves production. The present findings for chemical contents of different tobacco products is similar to that of several studies (Zhang et al., 2005; Suman et al., 2017; Kalicanin and Velimirovic, 2012; Engida and Chandravanshi, 2017).

\section{CONCLUSION}

This study was undertaken to analyze the concentration of different chemicals (toxicants) in major tobacco products available in Bangladesh. The results of this study provide an overview about the chemical contents in both smoke-based and smokeless tobacco products of Bangladesh. In this study, 
the concentration of four different chemicals namely Lead $(\mathrm{Pb})$, Cadmium $(\mathrm{Cd})$, Zinc $(\mathrm{Zn})$ and Nickel (Ni) were analyzed for different tobacco products. For loose leaf tobacco products the average concentrations of $\mathrm{Pb}, \mathrm{Cd}, \mathrm{Zn}$ and $\mathrm{Ni}$ were ranged from 15.5 to $18.7,3.02$ to $3.82,76.3$ to 85.7 and 20.5 to $27.7 \mathrm{mg} / \mathrm{L}$ respectively whereas for zarda the average concentrations of these chemicals were ranged from 7.38 to $8.67,1.94$ to $3.41,65.9$ to 97.2 and 15.2 to $18.7 \mathrm{mg} / \mathrm{L}$ respectively. The average concentrations of these chemicals obtained from cigarettes were ranged from 1.32 to 2.06, 0.98 to 2.4, 45.18 to 48.13 and 0.39 to $0.86 \mathrm{mg} / \mathrm{L}$ respectively. Finally in case of another selected tobacco products bidi the average concentration of these chemicals were ranged from 1.02 to $2.13,1.07$ to $2.19,28.9$ to 42.3 and 1.33 to $3.11 \mathrm{mg} / \mathrm{L}$ respectively. The study revealed that almost all analyzed tobacco products contained a relatively high concentration of heavy metals which increases the risk of different chronic diseases across the full life course as well as cancer. Therefore, it requires regulatory actions such as proper policy implementation as well as strengthening the existing rules and regulations and raising awareness to control tobacco cultivation and products processing. It is further suggested that close integration of basic research involving the tobacco crop production levels such as fertilizer use, pesticide regulation and application methods should be pursued and efforts should be made to reduce heavy metals concentrations.

\section{ACKNOWLEDGEMENT}

The study was conducted with technical input from the Bangladesh Center for Communication Programs (BCCP) and Institute for Global Tobacco Control, Baltimore, USA and financial support from the Bloomberg Initiative. The content is solely the responsibility of the researchers and does not necessarily represent the official views of BCCP. Technical assistance and continuous guidance provided by Dr. Md. Kapil Ahmed and Mr. H.M. Miraz Mahmud is greatly appreciated. The author gratefully acknowledges the BCCP Tobacco Grant Research Team members for their valuable comments, suggestions during the period of the study. Author acknowledges to all of the postgraduate students of the Department of Environmental Science, Bangladesh Agricultural University who are involved in sample collection, laboratory preparation, analysis in selected districts of Bangladesh.

\section{REFERENCES}

[1] De-beyer, J., Chris, L., Yurekli, A., 2001. Poverty and Tobacco. Tobacco Control, 10: 210-211.

[2] Dobaradaran, S., Schmidt, T.C., Nabipour, I., Ostovar, A., Raeisi, A., Saeedi, R., Khorsand, M., Khajeahmadi, N., Keshtkar, M. 2017. Cigarette butts abundance and association of mercury and lead along the Persian Gulf beach: an initial investigation. Environmental Science and Pollution Research, 25(6): 5465-5473.

[3] Edrydstephens, W., Calder, D. 2005. Source and health implications of high toxic metal concentrations in Illicit Tobacco Products. Environmental Science and Technology, 39: 479-488.

[4] Effroymson, D., Ahmed, S., Townsend, J., Alam, S.M., Dey, A.R., Saha, R., Dhar, B., Sujon, A.I., Ahmed, K.U., Rahman, O. 2001. Hungry for tobacco: An analysis of the economic impact of tobacco consumption on the poor in Bangladesh. Tobacco Control, 10(3): 212-217.

[5] Engida, A.M., Chandravanshi, B.S. 2017. Assessment of heavy metals in tobacco of cigarettes commonly sold in Ethiopia. Department of Chemistry, College of Natural Sciences, Addis Ababa University, Ethiopia. International Scientific Organization, 3(3): 212-218.

[6] Ezzati, M., Lopez, A.D., Rodgers, A., Hoorn, S.V., Murray, C.J.L. 2002. Selected major risk factors and global and regional burden of disease. The Lancet, 360:1347-1360.

[7] Food and Agricultural Organization (FAO). 2000. Tobacco: supply, demand and trade projections, Rome. FAO ESD Paper, 86.

[8] Gajalakshmi, V., Peto, R., Kanak, T.S., Jha, P. 2003. Smoking and mortality from tuberculosis and other diseases in India: retrospective study of 43000 adult male deaths and 35000 controls. The Lancet, 362, pp.507-715.

[9] Hossain, M.T., Hassi, U., Huq, S.M.I. 2018. Assessment of concentration and toxicological (Cancer) risk of lead, cadmium and chromium in tobacco products commonly available in Bangladesh. Department of Soil, Water \& Environment, University of Dhaka, Dhaka 1000, Bangladesh. 
[10] International Tobacco Control (ITC). 2010. Bangladesh National Report, The University of Waterloo, Waterloo-Ontario, Canada and the University of Dhaka, Dhaka, Bangladesh, pp. 9. Available at: http://www.itcproject.org/resources/view/60.

[11] Iwuoha, G.N., Oghu, E.I., Onwuachu, U.I., 2013. Levels of selected heavy metals in some brands of Cigarettes marketed in University of Port Harcourt, Rivers State. Department of Pure and Industrial Chemistry, University of Port Harcourt, Nigeria, 17: 561-564.

[12] Jung, M. C., Thornton, I., Chon, H. T. 1998. Arsenic, Cadmium, Copper, Lead, and Zinc Concentrations in Cigarettes Produced in Korea and the United Kingdom. Journal of Environmental Technology, 19: 237241.

[13] Kalicanin, B.,Nikolic, G., Nikolic, R. 2005. Ecologica,12: 297.

[14] Kalicanin, B.,Velimirovic, D. 2012. Potentiometric Stripping Analysis of Zinc, Cadmium and Lead in Tobacco Leaves (Nicotiana tabacum L.) and Soil Samples. International Journal Electrochemical Science, 7(1): 313-323.

[15] Lazarevic, K., Nikolic, D., Stosic, L., Milutinovic, S., Videnovic, J., Bogdanovic, D. 2012. Determination of lead and arsenic in tobacco and cigarette: An important issue of public health in Serbia. Central European Journal of Public Health, 20: 62-66.

[16] Miah, M. A., Hiya, H. J., Islam, M. A., Hossen, M. S., Khan, M. B. 2019. Assessment of Trace elements from Biomass burning and Household Dusts: Effects on Health and Environment. IOSR Journal of Environmental Science, Toxicology and Food Technology (IOSR-JESTFT), 13(2): 43-54.

[17] Murray, C.J., Lopez, A.D. 1996. The Global Burden of Disease. Geneva, World Health

[18] Organization, Harvard School of Public Health, World Bank.

[19] Murty, K.S.N., Tjell, J.C., Gopalachari, N.C. 1986. Lead and cadmium content of Indian flue-cured tobacco. Plant Soil, 95: 281-284.

[20] Musharraf, S.G., Shoaib, M., Siddiqui, A.J., Najam-ul-Haq, M., Ahmed, A. 2012. Quantitative Analysis of Some Important Metals and Metalloids in Tobacco Products by Inductively Coupled Plasma-Mass Spectrometry (ICP-MS). Chemistry Central Journal, 6(1), pp.56.

[21] Mussalo-Rauhamaa, H., Salmela, S. S., Leppaen, A., Pyysalo, H. 1986. Cigarettes as a Source of Some Trace and Heavy Metals and Pesticides in Man. Archives of Environmental Health, 4(1): 49-55.

[22] Nnorom, I. C. 2015. Copper, Iron and Zinc concentrations of tobacco leaves and ready-to-use snuff products on sale in Imo State Southeastern Nigeria. Journal of Applied Sciences and Environmental Management, 19(3): 459-467.

[23] Prabhakar, V., Jayakrishnan, G., Nair, S.V., Ranganathan, B. 2013. Determination of trace metals, moisture, $\mathrm{pH}$ and assessment of potential toxicity of selected smokeless tobacco products. Indian Journal of Pharmaceutical Sciences, 75(3): 262-269.

[24] Rahman, M. M., Islam, M. A., Khan, M. B. 2016. Status of heavy metal pollution of water and fishes in Balu and Brahmaputra rivers. Progressive Agriculture, 27(4):444-452.

[25] Regassa, G., Chandravanshi, B.S. 2016. Levels of heavy metals in the raw and processed Ethiopian tobacco leaves. Department of Chemistry, College of Natural Sciences, Addis Ababa University, Addis Ababa, Ethiopia. Springer Plus, 5: 232.

[26] Saldivar, L., Luna, M., Reyes, E., Soto, R., Fortoul, T.I. 1991. Cadmium determination in mexicanproduced tobacco. Environmental Research, 55: 91-96.

[27] Stojanovic, D., Nikic, D., Lazarevic, K. 2004. The level of nickel in smoker s blood and urine. Central European Journal of Public Health, 12: 187-189.

[28] Suman, S., Bhaumik, M., Dey, S.K. 2017. Heavy metals in different Indian tobacco products and their human health implications. Department of Biotechnology, Maulana Abul Kalam Azad University of Technology, India. World Journal of Pharmacy and Pharmaceutical Sciences, 6(10): 713-725.

[29] The Daily Star. 2016. Smoking and its harmful impact among students. [Published on: 25 December, 2016].

[30] Uddin, N., Islam, M. A., Baten, M. A. 2015. Heavy metal determination of brinjal cultivated in Soil with wastes. Progressive Agriculture, 27(4): 453-465.

[31] Watanabe, T., Kasahara, M., Nakatsuka, H., Ikeda, M. 1987. Cadmium and lead contents of cigarettes produced in various areas of the world. Science of the Total Environment, 66: 29-37.

[32] World Health Organization (WHO), 2007. Impact of Tobacco-related Illness in Bangladesh

[33] Regional Office for South-east Asia, pp. 32. Available at: http://www.who.int/iris/handle/. 
[34] World Health Organization (WHO), 2008. WHO Report on the Global Tobacco Epidemic. The MPOWER package: www.who.int/tobacco/mpower/en.

[35] World Health Organization (WHO), 2017. Lead. Environmental Health Criteria. WHO, Geneva, 165.

[36] Zaman, M. M., Nargis, N., 2007. Impact of tobacco related illnesses in Bangladesh. World Health Organization, Regional Office for South-East Asia.

[37] Zhang, C., Miura, J., Nagoas, Y., 2005. Determination of Cadmium, Zinc, Nickel and Cobalt in Tobacco by Reversed-Phase High-Performance Liquid Chromatography with 2-(8-Quinolylazo)-4,5diphenylimidazole as a Chelating Reagent. Analytical Science, 21(9): 1105-1110.

Citation: $M$ M Islam, M A Islam, P Biswas, S T Auyon, "Quantitative Analysis of Toxicants in Major Tobacco Products Available in Bangladesh", International Journal of Advanced Research in Chemical Science, 7(3), pp. 8-15. DOI: http://dx.doi.org/10.20431/2349-0403.0703002

Copyright: (C) 2020 Authors, This is an open-access article distributed under the terms of the Creative Commons Attribution License, which permits unrestricted use, distribution, and reproduction in any medium, provided the original author and source are credited. 